\title{
Perfil do Docente em Educação a Distância e suas Perspectivas Frente aos Processos Avaliativos
}

\author{
Alana M. de Morais ${ }^{1}$, Joseana M. F. R. de Araújo ${ }^{1}$, Evandro de B. Costa ${ }^{2}$ \\ ${ }^{1}$ Departamento de Informática - Universidade Federal de Campina Grande (UFCG) - \\ Campina Grande - PB - Brasil \\ ${ }^{2}$ Instituto de Informática - Universidade Federal de Alagoas (UFAL) - Maceió - AL - \\ Brasil \\ alanamorais@copin.ufcg.edu.br, joseana@computacao.ufcg.edu.br, \\ ebc.academico@gmail.com
}

\begin{abstract}
The increase of enrolments on Virtual Learning Environments demands on new teacher profile. However, there is a lack of reports comment on new teaching professional and their opinions. Consequently, this current paper aims to comment about teacher opinion in evaluation process within Virtual Learning Environments. Other objective of this paper is to define the sample profile of e-learning teacher. The initial findings showed some criticism about evaluation process in virtual class, and allowed the understanding about this new e-teacher.
\end{abstract}

Resumo. A expansão dos Ambientes Virtuais de Ensino e Aprendizagem (AVEA) trouxe consigo um novo perfil de docente. Contudo, detecta-se uma carência de estudos na literatura que discutam sobre tal profissional. Por isso, entender suas características é um passo fundamental na melhoria do processo de ensino e aprendizagem a distância. Neste sentido, este artigo investiga quem é este professor e discute suas perspectivas frente aos processos avaliativos nos AVEAs. Os resultados iniciais permitiram delinear o perfil deste profissional e registrar as principais criticas destes tomadores de decisão frente os processos de avaliação virtual.

\section{Introdução}

Desde o início da década, os números confirmam que as ações relacionadas à adoção de estratégias voltadas para Educação a Distância $(\mathrm{EaD})$ no Brasil e no mundo têm evoluído significativamente (ABED, 2012; ALLEN e SEAMAN, 2011). Neste sentido, tal panorama pode ser justificado pelas inúmeras pesquisas e investigações que intuíram aprimorar a dinâmica da área destacada e dos seus materiais pedagógicos, com destaque às melhorias relacionadas aos Ambientes Virtuais de Ensino e Aprendizagem (AVEAs)

Além disto, o crescimento da $\mathrm{EaD}$ tem exigido dos gestores educacionais e tomadores de decisão uma postura de questionamento crítico diante dos diversos cenários, para melhoria das estratégias pedagógicas adotadas nos presentes sistemas. Desse modo, é possível destacar as similaridades existentes entre o processo de planejamento, execução e avaliação entre o ensino presencial e o ensino a distância. 
Contudo, as distinções entre elementos chave nestas duas modalidades devem ser analisadas ao aplicá-las no contexto dos AVEAs.

Deste modo, a investigação sobre o perfil dos cursos, professores e alunos de $\mathrm{EaD}$ surge como uma alternativa plausível e necessária ao contexto de análise e amadurecimento dos cursos e disciplinas desta modalidade. Tal investigação torna possível a melhoria, por exemplo, das estratégias de execução de tarefas ou aspectos da interface, após o entendimento e interpretação dos dados coletados durante o processo de interação de professores com o AVEA.

Neste sentido, assumindo o pressuposto de que a EaD demanda um profissional cujo perfil se diferencie da modalidade presencial, surge a necessidade de delinear este docente e suas perspectivas, de forma a que se identifique e construa novos paradigmas didáticos e pedagógicos. Por isso, o presente artigo apresenta uma investigação sobre o perfil do docente e suas opiniões sobre os processos avaliativos nos AVEA. Além disto, outro objetivo desta investigação é entender as perspectivas deste tomador de decisões frente aos processos avaliativos nos ambientes citados.

Para isto, os pesquisadores propõem uma investigação, por meio da aplicação de questionários online, junto à comunidade acadêmica e aos docentes brasileiros de EaD. Assim, como principais resultados obtidos obteve-se: o delineamento do perfil do docente a distância entrevistado, a análise das opiniões dos professores sobre os processos avaliativos dos Recursos Pedagógicos (RPs) e identificação de correlações ao longo das análises. Neste sentido, entende-se por RP todo material pedagógico utilizado pelo professor no apoio ao processo de ensino aprendizagem nos AVEAs. Como exemplos de RP estão: fóruns de discussão, bate-papos, objetos de aprendizagem e questionários.

Ao final da análise, é possível caracterizar os docentes em sua maioria como profissionais do sexo feminino, com mais de 6 anos de experiência em cursos de EaD, com conhecimento avançado de Informática (ou seja, segurança do usuário em utilizar os recursos computacionais e criar suas próprias ferramentas de ensino), que utilizam seus materiais pedagógicos autorais e cadastram em média de 4 a 6 RPs por módulo do curso. Na perspectiva da avaliação dos RPs, os docentes apresentam uma forte preferência no uso de fóruns de discussão nos cursos. Além disso, algumas críticas são identificadas diante das possibilidades de avaliação dos alunos nos ambiente educacionais.

A fim de esclarecer o método científico utilizado e os resultados do estudo o trabalho está organizado em 5 seções principais. Na seção 2, discute-se a evolução do perfil do docente por meio de pesquisas e relatórios sobre a temática, o intuito desta seção é analisar a evolução deste perfil ao longo dos anos. Na terceira seção do presente artigo, o planejamento e execução das entrevistas são detalhados e discutidos. Além disto, a seção 4 contempla os principais resultados das investigação e responde alguns questionamentos ao longo da análise. Por fim, a seção 5 apresenta as considerações finais e os trabalhos futuros relacionados ao estudo.

\section{Perfil dos Professores de EaD}

Neste momento do artigo, o enfoque do trabalho são as pesquisas e relatórios acadêmicos que traçam o perfil do docente de EaD. Assim, é importante comentar sobre 
as diversas nomenclaturas dos agentes de $\mathrm{EaD}$ nos relatórios: tutor, facilitador, profissional docente, professor/tutor e professores independentes. Tal fato dificulta a investigação e a conceituação desse profissional formalmente.

Em primeiro lugar, é errôneo considerar que programas a distância minimizam o trabalho e a mediação do professor (MEC, 2007). Ao contrário, nos cursos superiores de $\mathrm{EaD}$, os professores veem suas funções se expandir, o que requer qualificação e habilidades específicas (ABED, 2008). Neste sentido, Peter (2001) é um dos primeiros a elencar componentes desejáveis ao comportamento docente de EaD: habilidades de escrever materiais específicos para a $\mathrm{EaD}$; disponibilidade de trabalhar com equipes multidisciplinares; capacidade de administrar e monitorar o processo de ensinoaprendizagem a distância e dinamicidade para realizar aulas presenciais para grupos pequenos.

Neste mesmo contexto, é interessante comentar sobre a publicação de Gouvêa e Cesar (2009). Os autores destacam em seu trabalho que os docentes de EaD devem ser dotados de uma habilidade de mediação e domínio da tecnologia para lidar com o processo de ensino-aprendizagem dos AVEA. Neste mesmo ano, o artigo de Lopes (2009) defende a necessidade de criação de cursos de formação de professores específicos para a EaD.

Diante dos relatórios e publicações analisados, aqueles que melhor apresentam e delineam o perfil dos professores de $\mathrm{EaD}$ no Brasil são os relatórios do Censo Ead. $\mathrm{Br}$ (ABED, 2010; ABED, 2012) e por isso merecem destaque. Os relatórios elaborados pelo grupo priorizam as seguintes temáticas: localização, experiência em $\mathrm{EaD}$, formação, obstáculos e preocupações pedagógicas do docente. Algumas constatações do relatório publicado em 2013 (ABED, 2012), sobre a EaD merecem comentários, tais como: metade dos docentes entrevistados estão localizados na Região Sudeste e 87,5\% desenvolvem ações em educação presencial e a distância. Outra informação interessante é que cerca de $47 \%$ dos professores atuam na $\mathrm{EaD}$ entre 3 e 5 anos. Quanto à formação, $19 \%$ dos entrevistados pertenciam à Pedagogia. Do total de professores independentes, $38 \%$ possuem mestrado e doutorado e $9 \%$ contam com especialização em outra área de conhecimento. Por fim, em relação aos obstáculos enfrentados em 2012, os professores indicam o custo de produção dos cursos $(20 \%)$ como o mais frequente e, em seguida, o suporte técnico para os participantes $(17,3 \%)$. A expectativa é de que esses obstáculos se mantenham em 2013.

Como é possível perceber, há uma carência de estudos que descrevam as características do docente explorando aspectos específicos do processo de ensino e aprendizagem virtual, principalmente no Brasil. Além disto, informações sobre os perfis destes profissionais e suas perspectivas sobre o processo educacional são pouco contemplados nestes relatórios. Por isto, este artigo destaca tal ponto como uma das contribuições da investigação realizada.

\section{Planejamento e Aplicação do Survey}

A presente seção do artigo tem o objetivo de discutir e apresentar as etapas percorridas no planejamento e aplicação dos questionários online utilizados no survey realizado. Inicialmente, são definidos o escopo do público-alvo e os objetivos do atividade planejada. O objetivo principal do questionário é identificar quem são os docentes que 
interagem com os AVEAs e como estes professores se comportam diante dos processos avaliativos do aluno nos AVEAs, mediante às ferramentas avaliativas disponíveis.

A estratégia adotada pelo estudo para extrair tais informações é a execução de uma investigação, por meio de um survey, junto à comunidade acadêmica entre o período de janeiro de 2014 até fevereiro de 2014.

\subsection{Público-alvo do questionário}

O questionário é composto por duas seções principais: perfil do professor e informações técnicas. A seção de perfil contempla questões relacionadas às características do professor e sua experiência. Concomitantemente, na seção de informações técnicas estão contempladas as questões relacionadas aos processos decisórios nos AVEAs. Além disto, a versão final do questionário foi disponibilizada por meio do formulário da ferramenta online do Google Drive.

O contato com os professores de $\mathrm{EaD}$ ocorre por meio de três estratégias distintas, são elas: contato direto com os professores de EaD que colaboravam com o grupo de pesquisa dos autores deste artigo, convite aos professores por meio das suas coordenações e lista de discussão da SBC. Neste sentido, o contato mediado pelos coordenadores de $\mathrm{EaD}$ atingiu um total de 15 coordenações, que foram convidadas a repassar o survey aos professores ou fornecer os contatos do corpo docente, pois a maioria dos endereços eletrônicos dos docentes são omitidos nos sítios eletrônicos dos cursos. Diante das respostas recebidas foram encaminhados mais de 120 emails convite para professores. Por fim, foi encaminhado um convite para a comunidade acadêmica, que pesquisa Informática na Educação, via grupo da SBC no Google, a fim de atingir os professores de EaD pesquisadores.

\subsection{Tamanho da Amostra}

As estratégias adotadas pelo presente estudo possibilitou a coleta de 111 respostas de professores de cursos brasileiros de $\mathrm{EaD}$ das mais distintas áreas do conhecimento. Diante destas informações, apenas quatro registros de repostas apresentaram falhas de preenchimento, totalizando ao final 107 respostas. Neste sentido, é importante comentar que a amostra coletada serve como um indicador do perfil e do comportamento apesar de representar uma parcela mínima dos docentes brasileiros em sua totalidade. Para que estes pontos fossem tratados como regra geral a aplicação do questionário precisaria ser ampliada.

\section{Resultados dos Questionários}

Após a aplicação dos questionários, é possível investigar os dois objetivos principais: delinear o perfil do professor de EaD entrevistado e discutir sobre as perspectivas deste frente aos processos avaliativos dos AVEAs. Esta seção do artigo apresenta os principais resultados destes dois momentos da pesquisa.

\subsection{Perfil do Docente de EaD}

No primeiro momento do presente trabalho investiga-se o perfil dos entrevistados por meio de informações relacionadas a área de atuação, experiência e informações pessoais. Como visto e comentado anteriormente, os trabalhos publicados sobre o perfil do 
docente em $\mathrm{EaD}$ se limitam a descrever tais características baseadas nas informações pessoais dos docentes.

Inicialmente é importante analisar os aspectos quantitativos dos dados obtidos de acordo com o perfil dos docentes entrevistados. A amostra é composta por uma parcela maior de professores de cursos de Ciências Exatas e Tecnológicas (52\% dos entrevistados), contrapondo as Ciências Biológicas (11\%) e as Ciências Humanas (37\%). Além disso, os dados contemplam entrevistados de todas as regiões do Brasil (Norte5\%, Nordeste- 44\%, Centro-Oeste- 9\%, Sudeste- 33\%, Sul- 9\%).

Outro aspecto analisado é o tempo de experiência do professor no campo da EaD. Neste caso, é possível identificar que os docentes entrevistados possuem experiência na área, pois apenas $24 \%$ da amostra era composta por professores com menos de três anos de experiência em cursos de EaD (Tabela 1). Este conhecimento prévio da área aumenta a confiança diante das opiniões e respostas dadas pelos educadores no questionário. Outro elemento interessante na análise quantitativa dos dados é a participação equivalente de professores do gênero masculino (46\%) e feminino (54\%) na amostra. Por fim, é relevante destacar que a maioria dos docentes consideravam seu nível de conhecimento em Informática como Avançado (52\%), frente aos que afirmam ter nível Intermediário (33\%) e a parcela mínima com conhecimento Básico (5\%). Tal informação indica que os educadores de EaD precisam se adaptar e desenvolver melhor as habilidades relacionadas aos aspectos tecnológicos.

Tabela 1. Características Demográficas dos Professores de EaD Brasileiros

\begin{tabular}{c|c|c}
\hline Categoria Demográfica & Característica & Percentual \\
\hline Gênero & Feminino & $54 \%$ \\
& Masculino & $46 \%$ \\
\hline Idade & Até 25 anos & $4 \%$ \\
& $26-36$ anos & $39 \%$ \\
& $37-46$ anos & $26 \%$ \\
& $47-56$ anos & $25 \%$ \\
\hline Experiência com Informática & Acima 57 anos & $6 \%$ \\
\hline Área de atuação & Básico & $5 \%$ \\
& Intermediário & $33 \%$ \\
& Avançado & $52 \%$ \\
\hline Experiência de ensino & Ciências Biológicas & $52 \%$ \\
& Ciências Humanas & $11 \%$ \\
& Menos de 5 anos & $37 \%$ \\
\hline Experiência com EaD & $6-10$ anos & $14 \%$ \\
& $11-15$ anos & $35 \%$ \\
& $16-20$ anos & $19 \%$ \\
& 21 anos ou mais & $11 \%$ \\
& Menos de 1 ano & $21 \%$ \\
\hline & $1-2$ anos & $8 \%$ \\
& $3-4$ anos & $15 \%$ \\
& $5-6$ anos & $28 \%$ \\
& 7 anos ou mais & $14 \%$ \\
& & $35 \%$ \\
\hline
\end{tabular}

Os resultados dos questionários possibilitam melhor entender o perfil do profissional entrevistado. É possível afirmar que se lida com uma maioria de mulheres, entre 26 e 36 anos, detentoras de um conhecimento avançado em Informática, com 6 a 
10 anos de experiência docentes (mais de 6 anos de experiência em EaD), associadas a diversas instituições de ensino (Tabela 1).

\subsection{Perspectivas do Docente frente aos Processos Avaliativos dos AVEA}

A segunda parte das análises se refere às informações técnicas sobre os processos avaliativos. Inicialmente, destaca-se o intuito de investigar a autoria dos materiais utilizados nos cursos. Neste sentido, quase 50\% dos RPs utilizados nos ambientes educacionais são de autoria do próprio professor (Figura 1), que cadastra em média de 4 a 6 RPs por módulo no curso (Figura 2).

O censo Ead.br (ABED, 2012) mostra em seus relatos que durante a avaliação da aprendizagem dos alunos a alternativa mais frequente para as instituições formadoras $(46,81 \%)$ e para as empresas fornecedoras $(25 \%)$ foi a de "questões objetivas online corrigidas pelo sistema"; já para os professores independentes $(51,61 \%)$, a maior parte das respostas incidiu na alternativa que aponta para "entrega de trabalho de pesquisa realizado a distância e corrigido por um educador".

É relevante comentar sobre o modelo de avaliação utilizado diante dos RPs entre os professores que participaram da pesquisa. Neste caso, investiga-se a relevância das ferramentas nas avaliações finais do aluno (Figura 3). Neste sentido, aproximadamente $45 \%$ dos professores afirmam que somente recursos pré-definidos tem suas interações analisadas, com o intuito de atribuir uma pontuação extra ao aluno. Por outro lado, há uma vertente de professores que analisam a qualidade da interação do aluno com os RPs, além da interação do aluno com a atividade. Porém, não esclarecem quais critérios são definidos nesta avaliação. O grupo formado por "Outro" é composto em sua totalidade por professores que afirmam utilizar os RPs como fonte principal durante os processos avaliativos.

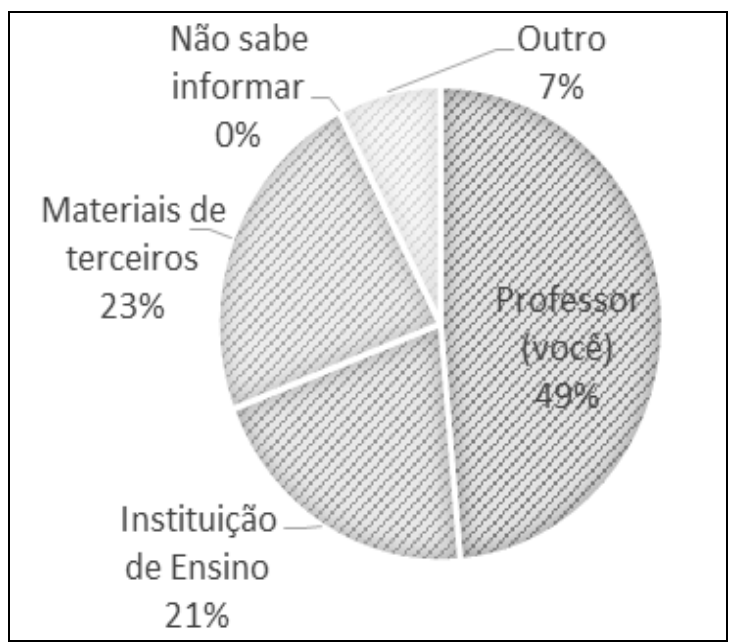

Figura 1. Autoria dos Recursos Pedagógicos

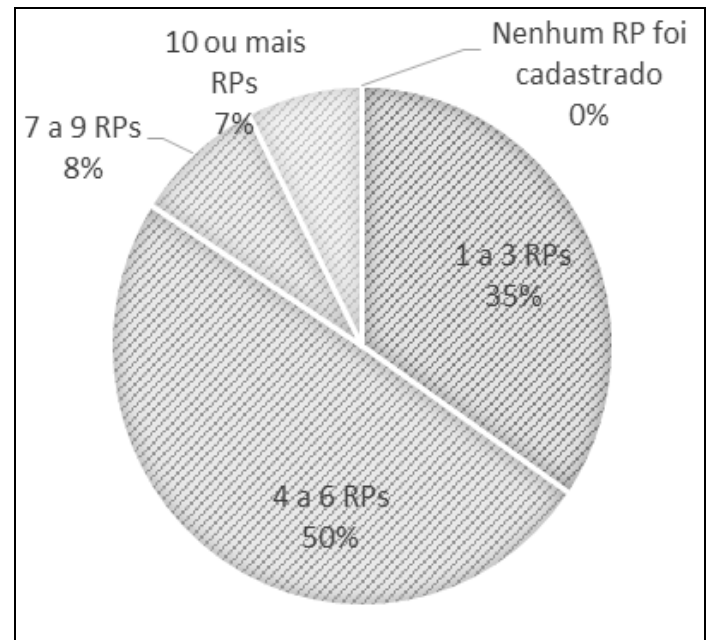

Figura 2. Número de RPs cadastrados pelos professores

Diante da diversidade de metodologias e softwares de avaliação existentes, a presente pesquisa quis entender como os RPs cadastrados são avaliados pelos professores para pontuar o desempenho do aluno. Nesta investigação, são removidos os docentes que afirmam na questão anterior que "Os RPs não são analisados, pois somente os projetos finais influenciam na avaliação”. A Figura 4 ilustra as respostas dadas pelos 
tomadores de decisão. Assim, destacou-se que 38\% das respostas dadas comentam sobre a importância de avaliar a qualidade das interações dos alunos com tais RPs. A frequência de interações com o RP é a segunda métrica destacada pelos professores e contabiliza quase $26 \%$ das respostas. Um indicador interessante nesta questão é o de docentes que afirmam avaliar os RPs de maneira integrada, cerca de $25 \%$ das respostas, ou seja, sob muitas dimensões pedagógicas (multidimensionalmente).

Os professores participantes da pesquisa confirmam que os fóruns de discussão são os RPs mais populares nos ambientes educacionais. A pesquisa demostra que tanto na avaliação da participação do aluno (Figura 5) quanto na avaliação da aprendizagem do aluno (Figura 6) esta realidade se mantém. Entre os RPs mais utilizados há ainda os questionários e relatórios.

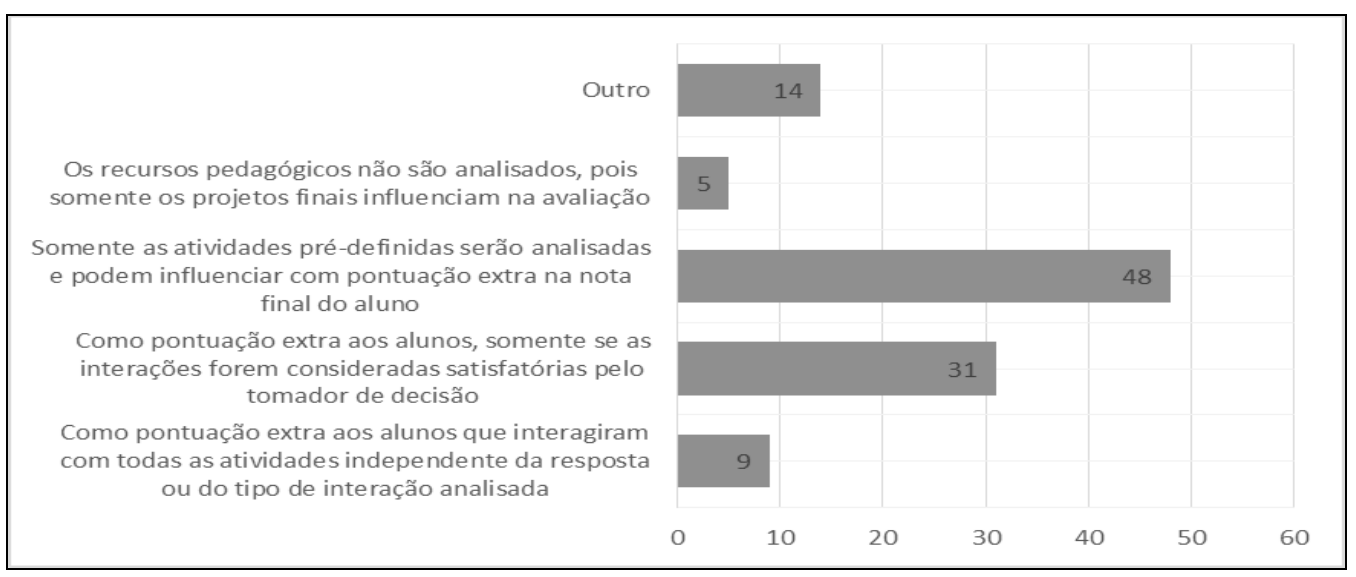

Figura 3. Importância dos RPs na nota final do aluno

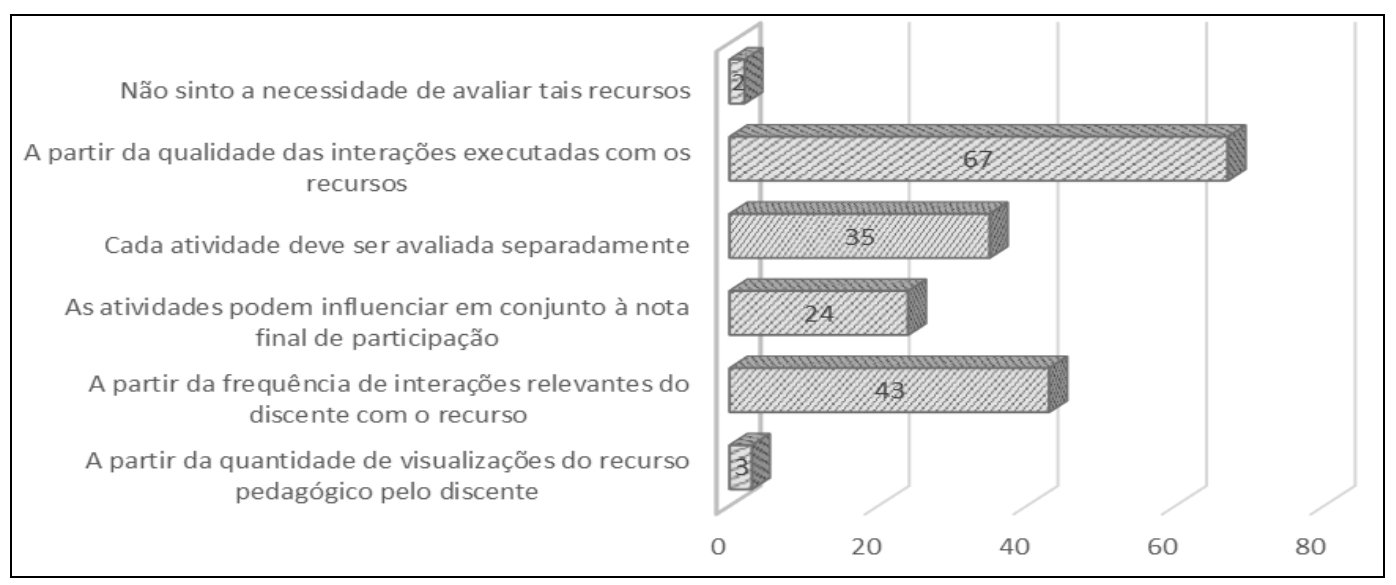

Figura 4. Critérios utilizados pelos professores para avaliar os RPs

A perspectiva dos docentes sobre os processos avaliativos os mostram que, de fato, eles consideram as ferramentas avaliativas (plug-ins de avaliação, relatórios de interação e desempenho, etc.) úteis ao tomador de decisão. Além disto, há aqueles que afirmam só utilizam as ferramentas associadas à fóruns e questionários ( $18 \%$ dos docentes participantes).

Segundo o relatório do Censo Ead.br (ABED, 2012), os pontos fracos destacados pelos docentes são: a participação em chat (44\%), a interação com os colegas $(42 \%)$ e a participação no fórum $(31 \%)$. Neste sentido, este estudo investiga 
quais são as críticas dos docentes em relação aos processos avaliativos e seu apoio nos ambientes educacionais. Os resultados mostra que há uma insatisfação do tomador de decisão frente aos recursos avaliativos disponíveis e ao apoio em dúvidas (Figura 7). Identifica-se que $30 \%$ dos professores comentam sobre a falta de ferramentas avaliativas nos ambientes em que trabalham, além disso 24\% afirmam que há pouco material de apoio ao tomador de decisão em momentos de dúvida. Quanto ao docentes que afirmam ter outras críticas relacionadas à avaliação há diversas respostas (11\% do total), entre elas: docentes que não possuem críticas e estão satisfeitos com os processos avaliativos do ambiente; críticas relacionadas ao número elevado de alunos por professor; críticas direcionadas ao ambiente TelEduc, que exige a nota e comentários/justificativas das mesmas; críticas relacionadas à frustração diante da falta de assistências das ferramentas no processo de revisão do que já foi avaliado e na automatização deste processo (com feedbacks ao docente), e lentidão do sistema.

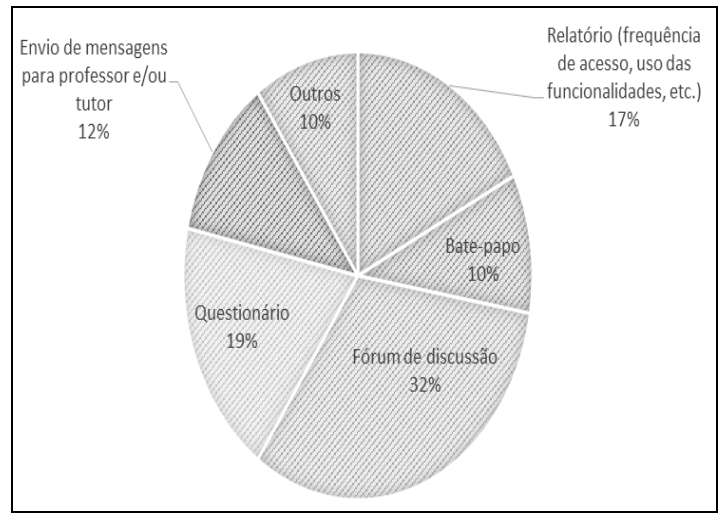

Figura 5. Critérios utilizados pelos professores para avaliar a Participação do aluno

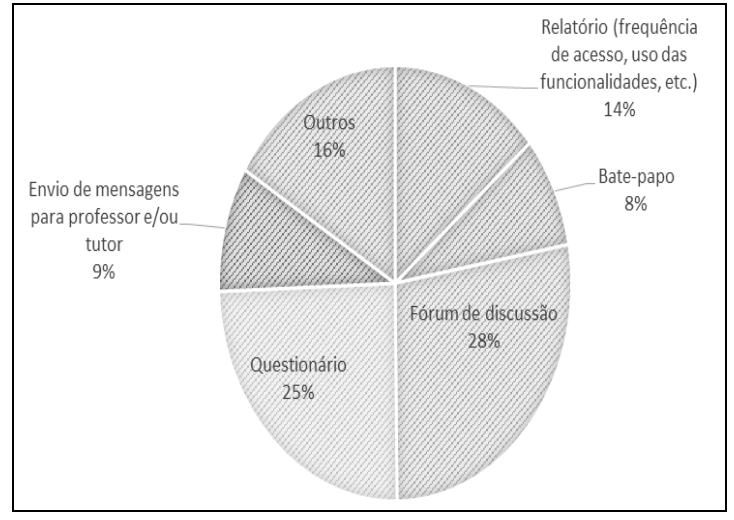

Figura 6. Critérios utilizados pelos professores para avaliar a Aprendizagem do aluno

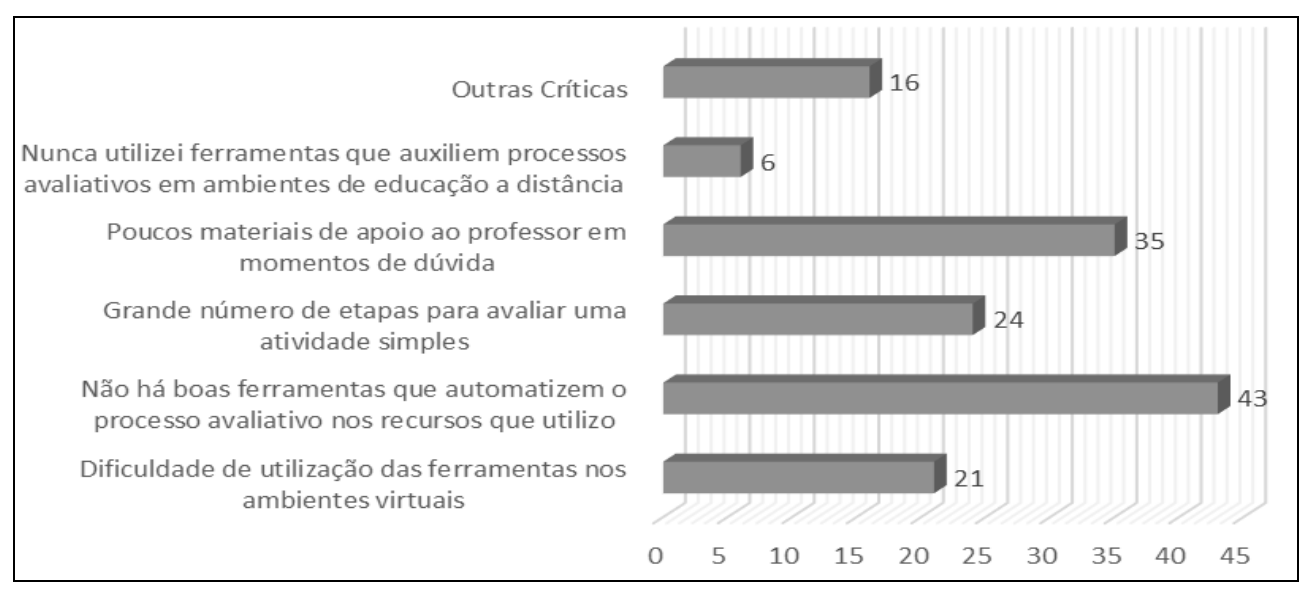

Figura 7. Principais críticas aos processos avaliativos dos AVEA

Por fim, é fundamental identificar se os docentes tem interesse em aplicar a metodologia de avaliação multidimensional diante da avalição dos RPs acessados pelo aluno. Os resultados nos mostram que $95 \%$ dos docentes entrevistados são positivos a tal metodologia avaliativa. Os 5\% referem-se aos professores satisfeitos com as ferramentas de avaliação disponibilizadas pelos AVEAs utilizados. Neste sentido, entende-se como multidimensionalidade a possibilidade de avaliar um aprendiz 
considerando diversos aspectos do processo de aprendizagem, não se limitando apenas ao critério desempenho ou qualidade.

\subsection{Análise de correlação sobre características extraídas do docente}

Por fim, esta etapa executa análises de correlações para extrair outras informações da amostra de entrevistados. As correlações são executadas por meio de testes de quiquadrado, pois alguns fatores da amostras se comportam de maneira não paramétrica. Este teste de hipótese se destina a encontrar um valor da dispersão para duas variáveis nominais, avaliando a associação existente entre variáveis qualitativas. Tal teste é não paramétrico, ou seja, não depende dos parâmetros populacionais, como média e variância. Assim, diante das variáveis obtidas e das características analisadas, as principais constatações obtidas no estudo são:

\section{a) Conhecimento informática $x$ Avaliação multidimensional}

Há associação entre o grau de conhecimento de Informática do docente e o fato dele ter interesse em uma futura ferramenta de avaliação multidimensional. Isto é perceptível ao se identificar que somente professores com nível de conhecimento Avançado $(4,673 \%$ dos entrevistados) se mostram desinteressados na ferramenta de avaliação multidimensional. Uma associação entre conhecimento de Informática e a Intenção de avaliar multidimensionalmente os alunos foi encontrado que, $\chi^{2}(2, \mathrm{~N}=107)$ $=3,258318, \mathrm{p}>0,05$. As frequências das células mostram que quase $60 \%$ dos professores com conhecimento Avançado tem a intenção de usar a abordagem multidimensional. Contraponto os outros grupos de especialistas (Básico e Intermediário) com menos de 33\% cada um.

\section{b) Experiência de docência $x$ Quantidade de Recursos cadastrados}

A experiência com a docência apresenta dependência com a quantidade de RPs cadastrados pelo professor no AVEA. Há uma tendência de todos os grupos de professores cadastrarem entre 4 a 9 RPs por módulo criado. Contudo, os grupos de professores que cadastram de 1 a 3 Recursos está concentrado entre o grupo de 6 a 10 anos de docência. Tal fato, não significa que este grupo peca por usar poucos RPs. Há a possibilidade deste grupo utilizar RPs que englobem diversas atividades ou outras tecnologias educacionais podem estar associadas ao material, não há como afirmar isto.

\section{c) Avaliação da participação x Avaliação da aprendizagem}

Outro investigação interessante é a relação entre a avalição da aprendizagem com a avaliação da participação por parte dos docentes entrevistados. Os resultados da aplicação do teste qui-quadrado de Pearson demostra que há independência entre as variáveis "Avaliacao_Aprendizagem" e a variável "Avaliacao_Participacao". Esta informação foi obtida porque $\chi^{2}(2772, \mathrm{~N}=107)=3644,066 ; \mathrm{p}<0,05$. Estes valores permitem afirmar que os professores avaliam de maneira independente a aprendizagem do aluno e sua participação no ambiente de aprendizagem.

\section{Considerações Finais}

Diante das informações apresentadas foi possível delinear um perfil de professor e entender as críticas e opiniões deste profissional frente aos processos avaliativos dos AVEA. Entender quem são estes profissionais é uma forma de melhor apoiá-los e treiná- 
los frente a esta modalidade de cursos tão desafiadoras. Assim, a carência de levantamentos sobre a temática foi o principal aspecto para a realização do presente estudo. Além disso, esta investigação se propôs a identificar os processos avaliativos sobre o ponto de vista do professor, que foi realizada sob duas perspectivas principais: a avaliação da aprendizagem e a avaliação da participação. Tais abordagens devem ter metodologias avaliativas diferenciadas, apesar da participação poder influenciar na avaliação da aprendizagem. $\mathrm{O}$ que se encontrou na pesquisa foi a aplicação das mesmas técnicas de avaliação formativa nestes dois aspectos analisados, ou seja, os docentes utilizam os mesmos RPs e ferramentas para analisar fatores pedagogicamente diferenciados. Identificou-se uma preferência dos docentes em analisar os fóruns de discussão e os questionários. Encontraram-se diversas críticas quanto a automatização de alguns processos em tais ferramentas. Por exemplo, o elevado tempo e esforço na avaliação de mensagens de fóruns.

Neste sentido, há diversos trabalhos futuros para a presente pesquisa. Inicialmente, identificar como as dinâmicas pedagógicas do professor podem ser melhoradas no ambientes educacionais. Outra atividade relevante seria investigar por meio de uma análise qualitativa informações que ainda podem ser extraídas dos dados coletados. Por fim, propor uma modelagem de avaliação formativa multidimensional a fim de otimizar o processo de análise do professor, explorando inicialmente os RPs mais populares entre os docentes.

Finalmente, é necessário agradecer aos 111 professores entrevistados que responderam ao questionário de forma voluntária.

\section{References}

ABED. Associação Brasileira De Educação A Distância. (2008). Anuário Brasileiro Estatístico de Educação Aberta e a Distância, 2008. 4. ed. São Paulo. 2008.

ABED. Associação Brasileira De Educação A Distância. (2010). "Censo ead.br. 2010. Associação Brasileira de Educação a Distância". São Paulo: Pearson Education.

ABED. Associação Brasileira De Educação A Distância. (2012) "Censo ead.br: Analytic Report of Distance Learning in Brazil". Versão 1'. São Paulo, Pearson, 2012.

Allen, I. E. e Seaman, J. (2014). "Changing Course: Ten Years of Tracking Online Education in the United States". Sloan Consortium. PO Box 1238, Newburyport, MA 01950, 2013. Disponível em: onlinelearningsurvey.com/reports/changingcourse.pdf. Acesso em: 10. mar. 2014.

Gouvêa, F. R. e Cesar, M. (2009). O professor de EAD: um perfil. Trabalho apresentado no 15 Congresso Internacional ABED de Educação a Distância, Fortaleza, CE.

Lopes, N. M. (2009) "O perfil profissional do professor de ensino superior na EaD e suas perspectivas, a partir da análise dos profissionais que atuam em uma instituição de Ipatinga". Associação brasileira de educação a distância, São Paulo (2009).

MEC. (2007) Referenciais de Qualidade para Educação Superior a Distância. Disponível em: http://portal.mec.gov.br/seed/arquivos/pdf/legislacao/refead1.pdf. Acessado em: 17 jun. 2014.

Peters, O. (2001) Didática do ensino a distância. São Leopoldo: UNISINOS. 